\title{
A new era for monoclonal antibodies with applications in neurology (Review)
}

\author{
CARMEN ADELLA SIRBU ${ }^{1,2^{*}}$, MINERVA CLAUDIA GHINESCU ${ }^{1 *}$, \\ ANY DOCU AXELERAD ${ }^{3,4}$, ANCA MARIA SIRBU ${ }^{5 *}$ and FLORENTINA IONITA-RADU ${ }^{1,6}$
}

\author{
${ }^{1}$ Department of Medical-Surgical and Prophylactic Disciplines, Faculty of Medicine, 'Titu Maiorescu' University, \\ 031593 Bucharest; ${ }^{2}$ Department of Neurology, 'Carol Davila' Central Military Emergency University Hospital, \\ 010242 Bucharest; ${ }^{3}$ Department of Neurology, Faculty of Medicine, 'Ovidius' University of Constanta, \\ 900470 Constanta; ${ }^{4}$ Department of Neurology, 'St. Apostol Andrei' Clinical Emergency Hospital, \\ 900591 Constanta; ${ }^{5}$ Department of Endocrinology, 'C.I. Parhon' National Institute of Endocrinology, \\ 011863 Bucharest; ${ }^{6}$ Department of Gastroenterology, 'Carol Davila' Central Military \\ Emergency University Hospital, 010242 Bucharest, Romania
}

Received June 3, 2020; Accepted July 3, 2020

DOI: 10.3892/etm.2020.9519

\begin{abstract}
Medical research continues to focus on developing specific treatment strategies, including biological products that are effective and have a good safety profile. Due to their novelty, an updated overall view is offered on some neurological diseases which benefit from monoclonal antibodies (mAbs), for better treatment in clinical decisions. An extensive literature review was performed using PubMed with the following search terms: 'monoclonal antibodies' and 'history of monoclonal antibodies' and 'monoclonal antibodies in neurology'. The following information was collected: the era before the discoveries of mAbs, the stage of implementation of biotechnologies for mAbs, and the clinical trials submitted at https://clinicaltrials.gov/ with patients suffering from neurological diseases treated with mAbs. Since 2004, mAbs have been used to treat several neurological diseases, yielding new therapeutic perspectives: natalizumab, alemtuzumab and ocrelizumab for multiple sclerosis, eculizumab for myasthenia gravis, erenumab and frenazumab for migraine, galcanezumab for migraine and cluster headache, eculizumab for neuromyelitis optica spectrum disorder. As in other cases, drug repurposing is applied to monoclonal antibodies, saving time and money. These innovative therapies are more effective and can treat previously untreatable diseases. As better understanding of the pathogenic mechanisms of
\end{abstract}

Correspondence to: Dr Any Docu Axelerad, Department of Neurology, Faculty of Medicine, 'Ovidius' University of Constanta, Campus, 1 Aleea Universității, Corp B, 900470 Constanta, Romania E-mail: docuaxi@yahoo.com

${ }^{*}$ Contributed equally

Key words: monoclonal antibodies, multiple sclerosis, migraine, myasthenia gravis, cluster headache, neuromyelitis optica spectrum disorders, multiple sclerosis neurological diseases is gained, additional $\mathrm{mAbs}$ are expected to be developed at a lower cost and with better safety profile compared with current treatment options.

\section{Contents}

1. Introduction

2. A glance at the discovery of mAbs

3. Monoclonal antibodies for neurological diseases

4. Conclusions

\section{Introduction}

Medical research is actively focusing on developing specific treatments that are highly effective and show a good safety profile. Biological therapy is an important step in this direction. The European Medicine Agency defines biological products as 'medicines containing one or more active substances produced or obtained from a biological source (1).

Examples of biological drugs include various proteins such as insulin; growth hormones; and various other substances obtained through the processing of human blood, organs, and animal tissues, such as vaccines and recombinant DNA $(2,3)$.

In an official act of 1922 , the Romanian scientist Nicolae Paulescu stated 'In order for pancreine to be used for the treatment of diabetes in humans, it must be prepared in large quantities, which requires a large capital' (4). Such technological difficulties in obtaining biological products for therapy have been overcome through the development of diverse biotechnological advances. The first license obtained for a product using recombinant DNA technology was for insulin in 1982. Genetic engineering techniques have since been used to produce monoclonal antibodies (mAbs), which have broad applications as diagnostic, prophylactic, and therapeutic agents. In the present review, we chronicle the discovery 
of mAbs and their rise to prominence throughout medical science, with a focus on neurological diseases.

\section{A glance at the discovery of $\mathrm{mAbs}$}

At the end of the 19th century, Wilhelm Roux (1850-1924), the pioneer of experimental embryology, demonstrated that it was possible to preserve living cells (derived from chicken embryos) outside of the body in a suitable environment for several days. Later, Montrose Burrows (1884-1947), surgeon and pathologist, together with Alexis Carrel (1873-1944), developed cell cultures of different embryonic and adult tissues (skin, connective tissue, cartilage, bone, periosteum, bone marrow, kidney, and thyroid) of several species, which were preserved in vitro using fresh plasma from the same source as the tissues $(5,6)$.

The German physiologist Emil von Behring (1854-1917), trained by Robert Koch, received the Nobel Prize in Physiology in 1901 for discovering the diphtheria antitoxin with his colleague Erich Wernicke. In 1890, von Behring, together with the Japanese scientist Kitasato, published an article on the discovery of antitoxins against diphtheria and tetanus (7). They injected diphtheria and tetanus toxins into laboratory rats, goats, and horses, which then developed immunity. Thus, they demonstrated that non-immunised animals can be protected from bacterial toxins by injecting antitoxins (antitoxic serum) from immunised animals, practically laying the groundwork for passive immunization $(8,9)$. In doing so, they paved the way for the discovery of antibodies and antigens.

Antibodies were discovered in 1962 by the British biochemist Rodney Robert Porter (1917-1985), who together with Gerald M. Edelman (1929-2014), received the Nobel Prize for Physiology. Antibodies are proteins that are secreted by plasmocytes, which in turn originate from type B lymphocytes $(10,11)$. The first technology for synthesizing mAbs under laboratory conditions was developed by Georges Köhler and Cesar Milstein from Cambridge. They fused an antibody-producing cell with a tumour cell, allowing the unlimited production of an antibody. Their research, in the form of a three-page report, was published in 1975 in Nature and has accumulated up to 10,000 citations to date (12). The proposed technology (obtaining hybridomas) involved several stages: immunization of laboratory mice against a known antigen, removal of B lymphocytes from the mouse spleen (antibody-producing cells), and their binding to myeloma cells, which can continuously synthesise antibodies against the known antigen. Milstein and Köhler received the Nobel Prize in Physiology/Medicine for their research in 1984. Their technique has been used for the diagnosis and treatment of diseases and has generated a global biotechnology industry worth billions of pounds (13).

In $1979, \mathrm{mAbs}$ were developed for the first time, by Philip Stashenko and Lee Nadler. These antibodies were artificially synthesised from mouse cells against antigens on the surface of cancer cells in human subjects with lymphoma. However, a small number of murine antibodies connected to tumour antigens were perceived as foreign cells (antigens) by the human body (14-16). In 1986, the FDA approved the first therapeutic $\mathrm{mAb}$, muromonab-CD3. This antibody reduces kidney transplant rejection through selective immunosuppressive effects (17). However, after prolonged use of murine
$\mathrm{mAbs}$, their efficacy is greatly diminished by the development of human anti-murine antibodies (HAMA) (18).

In the early 1990s, second-generation biological therapies were introduced. Using molecular methods based on recombinant DNA technology, chimeric mAbs were synthesised with variable murine regions and constant human regions $(19,20)$. As a result, HAMA were formed in much smaller amounts, and these antibodies were significantly more effective in patients. The third generation of biological therapies based on humanised antibodies appeared in the late 1990s. The reduction in the percentage of murine amino acid sequences in mAbs further decreased their immunogenicity in the human body (21).

With ongoing improvements in genetic engineering and the development of transgenic mouse technology, human mAbs were obtained in 2000 . These antibodies have many advantages, such as specificity, selectivity, homogeneity, low toxicity, and ease of production in large quantities. However, the use of these antibodies was limited by their high molecular weight, inability to penetrate deeply into tissues, and low permeability through the plasma membrane. The high production costs, reversibility of binding to target molecules, and difficulties in the administration of human mAbs remain challenges to date (22-24).

The multitude of mAbs with therapeutic value approved or being tested in clinical studies led to the elaboration of a unified nomenclature by the World Health Organization in October 2008. This nomenclature considers the target on which the antibody acts and the source of the antibody. There is a common suffix, mab, which is an abbreviation of 'monoclonal antibody', and a prefix that confers the uniqueness of the name (25). There are four categories of clinically relevant $m A b s$ : murine (100\% murine protein), with the suffix-omab (blinatumomab for acute lymphoblastic leukaemia, ibritumomab tiuxetan for non-Hodgkin lymphoma); chimeric (30\% murine protein), with the suffix -ximab (dinutuximab for paediatric neuroblastoma, infliximab for Crohn's disease); humanised (5-10\% murine protein), with the suffix -zumab (natalizumab for multiple sclerosis, benralizumab for asthma); and human, (100\% human proteins) with the suffix -umab (brodalumab for psoriasis, durvalumab for urothelial carcinoma) (10).

For these molecules to be safe and therapeutically effective, they are expected to possess high affinity for the target antigen, low immunogenicity for the body, and a high half-life value. By 2018, the FDA approved $80 \mathrm{mAbs}$, of which 10 were approved in 2015, 10 in 2016, and 17 in 2017. These 3 years account for $\sim 50 \%$ of the total number of mAbs approved by 2018 , revealing the dynamic nature of this field (17). In 2015, the global market for mAbs was sevenfold larger than that in 2005, with sales of US $\$ 98$ trillion. More than half of the biopharmaceutical sales were attributed to mAbs (26). Most $\mathrm{mAbs}$ currently available are used to treat cancer (38.9\%), autoimmune diseases (25\%), organ transplantation (8.3\%), genetic diseases (6.9\%), infectious diseases (5.5\%), asthma (4.2\%), cardiovascular diseases (4.2\%), haematological diseases (4.2\%), and macular dystrophies (2.8\%) (27-30).

\section{Monoclonal antibodies for neurological diseases}

Multiple sclerosis. Natalizumab was the first humanised $\mathrm{mAb}$ to be approved by the FDA in 2004 for relapsing remitting 
multiple sclerosis treatment. The treatment involved monthly infusion of $300 \mathrm{mg}$ blocks of VLA-4 integrin and lymphocyte transport through the blood-brain barrier, with continued immunosuppression. Because of life-threatening infection with John Cunningham polyomavirus, the FDA stopped the use of natalizumab for a couple of months until 2006 , when it was reapproved. In June 2016, 152,500 patients were treated worldwide with natalizumab (for multiple sclerosis and Crohn's disease), including 667 progressive multifocal leucoencephalopathy cases. Since 2007, natalizumab has been under Risk Evaluation and Mitigation Strategy platform rules and has a black box warning label.

Alemtuzumab was the second humanised mAb CD52 drug approved by the FDA in November 2014, 10 years after natalizumab. After this $\mathrm{mAb}$ was repurposed to treat chronic B-cell lymphocytic leukaemia, alemtuzumab was released for treating relapsing multiple sclerosis. In April 2019, the EMA restricted its use for multiple sclerosis until new data became available, because it induced life-threatening reactions (myocardial infarction, stroke). Injection-related reactions, infections, autoimmune disorders, and malignancy were reported as drug side effects. The first dose is $12 \mathrm{mg}$ intravenously over $4 \mathrm{~h}$ daily for 5 consecutive days; 12 months later, a second dose is administered for 3 consecutive days, and then, a maintenance dose is administered annually. This pulsed immunosuppressive therapy has a persistent effect but a high risk of reactivating latent infections and autoimmunity.

Ocrelizumab was approved for primary progressive and relapsing remitting multiple sclerosis by the FDA in March 2017. This fully humanised IgG CD20 antibody was the first drug approved for primary progressive multiple sclerosis. Administration by infusion provokes more frequent and intense local reactions compared with other mAbs (31).

Myasthenia gravis. The complement plays an important role in acetylcholine receptor degradation, leading to abnormalities in the postsynaptic membrane. One way to treat myasthenia gravis is by inhibiting complement activation and membrane attack complex formation.

Eculizumab was the first mAb approved worldwide for complement-mediated disease therapy (paroxysmal nocturnal haemoglobinuria in 2007 and atypical haemolytic uraemic syndrome in 2011). This drug was repurposed and approved by the FDA in 2018 for treating generalised anti-acetylcholine receptor antibody-positive myasthenia gravis. By blocking complement activation (binding to the $\mathrm{C} 5$ protein), this $\mathrm{mAb}$ preserves the postsynaptic membrane and acetylcholine receptor function. The recommended dose is $900 \mathrm{mg}$ intravenously every week for the first month, 1,200 mg intravenously at week 5 , and then, the same dose every 2 weeks. Adverse events include musculoskeletal pain, nasopharyngitis, and headache. Prior to starting treatment, the Neisseria meningitis vaccine is mandatory because of the risk of meningitis. Eculizumab is under a Risk Evaluation and Mitigation Strategy because of its safety profile (32).

Migraine. Erenumab was the first mAb approved in July 2018 by the FDA and EMA for the treatment of chronic or episodic migraine, under additional monitoring. It blocks the calcitonin gene-related peptide (CGRP).
The overactivity of CGRP, involved in vasodilatation, is a well-known mechanism in migraine. People with more than 4 days of migraine per month are eligible for this treatment, administered at a monthly dose of 70 or $140 \mathrm{mg}$, by injection. Common adverse reactions include injection site reactions (pain and erythema), cramps, muscle spasms, fatigue, pruritus, and constipation.

A few months later, galcanezumab was authorised for the preventive treatment of migraine in adults by the FDA and EMA as a self-administered, subcutaneous injection of $120 \mathrm{mg}$ once a month (33).

Fremanezumab was approved in March 2019 for the prophylaxis of migraine under additional monitoring. The recommended dose is $225 \mathrm{mg}$ subcutaneously monthly or $675 \mathrm{mg}$ every 3 months. The Institute for Safe Medication Practices reported some adverse effects of this new class of drugs for migraine. Constipation was the most frequently reported adverse effect. Others included alopecia, muscle disorders, hypersensitivity (rash, erythema, pruritus, swelling, and anaphylaxis), psychiatric complaints, and cardiac events, (syncope, palpitations, arrhythmias, heart arrest) (34). The American Headache Society recommends CGRP antagonists only in patients who have an inadequate response to or are unable to tolerate oral preventive therapies (35).

Cluster headache. In June 2019, the FDA approved galcanezumab-gnlm for episodic cluster headache in adults. This innovative drug can be self-administered subcutaneously at the onset of a cluster headache period.

Every month, until the end of the cluster period (typically 2 weeks to 3 months), a dose of $300 \mathrm{mg}$ is mandatory. Among people with cluster headache, $85-90 \%$ have the episodic form. Some hypersensitivity reactions occur within a few days after administration (rash, urticaria, dyspnoea, angioedema, anaphylaxis, anti-drug antibodies). Injection site reactions were the most common effects (36).

Neuromyelitis optica spectrum disorder. Eculizumab was approved in June 2019 by the FDA for intravenous treatment of neuromyelitis optica spectrum disorder (NMOSD), only for adult patients with anti-aquaporin-4 (AQP4) antibodies.

This neuroinflammatory autoimmune disease is associated with an autoantibody directed against AQP4, an astrocytic water channel protein. Complement-induced cytotoxicity attacks the astrocytes, showing beneficial effects (37). The therapeutic regimen is the same as that for myasthenia gravis, at $1,200 \mathrm{mg}$ every 2 weeks, after the initial 5-week treatment period. Adverse effects include arthralgia, back pain, nasopharyngitis, influenza, dizziness, and diarrhoea. Boxed warnings are provided on the drug label because of the risk of life-threatening meningococcal infection (38).

\section{Conclusions}

Technological advancements have enabled the development of $\mathrm{mAb}$ therapies for a range of clinical applications. The field of mAbs is characterised by limitations, as well as new findings and Nobel prizes, in the pursuit of a technology that can treat previously untreatable diseases. As the understanding of the pathogenic mechanisms of diseases increases, additional 
mAbs are expected to be developed at a lower cost and with fewer side effects compared with current treatment options.

\section{Acknowledgements}

Not applicable.

\section{Funding}

No funding was received.

\section{Availability of data and materials}

Not applicable.

\section{Authors' contributions}

All the authors substantially contributed to each of the following aspects of this review paper: Conception and design of the study (mainly CAS, MCG and FIR), literature research and analysis and interpretation of the relevant data (mainly CAS, ADA, AMS and MCG). In addition, all authors were involved in the drafting of the manuscript (mainly CAS, AMS and FIR) and revised it critically for important intellectual content (mainly MCG, ADA and AMS). All authors have read and approved the final version of the manuscript. The authors have participated sufficiently in the study, take public responsibility for appropriate portions of the content and agree to be accountable for all aspects of the work in ensuring that questions related to the accuracy or integrity of any part of the work are appropriately investigated and resolved.

\section{Ethics approval and consent to participate}

Not applicable.

\section{Patient consent for publication}

Not applicable.

\section{Competing interests}

The authors declare that they have no competing interests.

\section{References}

1. Wolff-Holz E, Tiitso K, Vleminckx C and Weise M: Evolution of the EU biosimilar framework: Past and future. BioDrugs 33: 621-634, 2019

2. Malaviya AN and Mehra NK: A fascinating story of the discovery and development of biologicals for use in clinical medicine. Indian J Med Res 148: 263-278, 2018.

3. Sirbu CA, Sirbu OM, Constantin C and Sandu AM: Neuroimunotoxicity of aluminium. Farmacia 63: 8-10, 2015.

4. de Leiva A, Brugués E and de Leiva-Pérez A: The discovery of insulin: Continued controversies after ninety years. Endocrinol Nutr 58: 449-456, 2011 (In Spanish).

5. Carrel A: Cultivation of adult tissues and organs outside of the human body. JAMA 55: 1379-1381, 1910.

6. Rodriguez-Hernandez CO, Torres-Garcia SE, Olvera-SandovalC, Ramirez-Castillo FY, Muro AL, Avelar-Gonzalez FJ and Guerrero-Barrera AL: Cell culture: History, development and prospects. Int J Curr Res Acad Rev 2: 188-200, 2014.
7. von Behring E and Kitasato S: The mechanism of immunity in animals to diphtheria and tetanus. Deutscbe Mediziniscbe W'ochenschift 16: 1145-1148, 1890.

8. Kaufmann SH: Remembering Emil von Behring: From tetanus treatment to antibody cooperation with phagocytes. MBio 8: e00117-e17, 2017.

9. Llewelyn MB, Hawkins RE and Russell SJ: Discovery of antibodies. BMJ 305: 1269-1272, 1992.

10. Buss NA, Henderson SJ, McFarlane M, Shenton JM and de Haan L: Monoclonal antibody therapeutics: History and future. Curr Opin Pharmacol 12: 615-622, 2012.

11. Hawkins RE, Llewelyn MB and Russell SJ: Adapting antibodies for clinical use. BMJ 305: 1348-1352, 1992.

12. Köhler G and Milstein C: Continuous cultures of fused cells secreting antibody of predefined specificity. Nature 256: 495-497, 1975.

13. Liu JK: The history of monoclonal antibody development Progress, remaining challenges and future innovations. Ann Med Surg (Lond) 3: 113-116, 2014.

14. Nadler LM, Stashenko P, Hardy R, Kaplan WD, Button LN, Kufe DW, Antman KH and Schlossman SF: Serotherapy of a patient with a monoclonal antibody directed against a human lymphoma-associated antigen. Cancer Res 40: 3147-3154, 1980.

15. Nadler LM, Stashenko P, Hardy R and Schlossman SF: A monoclonal antibody defining a lymphoma-associated antigen in man. J Immunol 125: 570-577, 1980.

16. Nadler LM, Stashenko P, Hardy R, Tomaselli KJ, Yunis EJ, Schlossman SF and Pesando JM: Monoclonal antibody identifies a new Ia-like (p29,34) polymorphic system linked to the HLA-D/DR region. Nature 290: 591-593, 1981.

17. Cai HH: Therapeutic monoclonal antibodies approved by FDA in 2017. MOJ Immunol 6: 82-84, 2018.

18. Tjandra JJ, Ramadi L and McKenzie IF: Development of human anti-murine antibody (HAMA) response in patients. Immunol Cell Biol 68: 367-376, 1990

19. Jones PT, Dear PH, Foote J, Neuberger MS and Winter G: Replacing the complementarity-determining regions in a human antibody with those from a mouse. Nature 321: 522-525, 1986.

20. Morrison SL, Johnson MJ, Herzenberg LA and Oi VT: Chimeric human antibody molecules: Mouse antigen-binding domains with human constant region domains. Proc Natl Acad Sci USA 81: 6851-6855, 1984

21. Boulianne GL, Hozumi N and Shulman MJ: Production of functional chimaeric mouse/human antibody. Nature 312: 643-646, 1984.

22. Chames P, Van Regenmortel M, Weiss E and Baty D: Therapeutic antibodies: Successes, limitations and hopes for the future. Br J Pharmacol 157: 220-233, 2009.

23. Foltz IN, Gunasekaran K and King CT: Discovery and bio-optimization of human antibody therapeutics using the XenoMouse ${ }^{\circledR}$ transgenic mouse platform. Immunol Rev 270: 51-64, 2016.

24. Scott CT: Mice with a human touch. Nat Biotechnol 25: 1075-1077, 2007.

25. Mayrhofer P and Kunert R: Nomenclature of humanized mAbs: Early concepts, current challenges and future perspectives. Hum Antibodies 27: 37-51, 2019.

26. Lai Y, Wang R, Chen X, Tang D, Hu Y, Cai J, Zhang Q and $\mathrm{Hu} \mathrm{H}$ : Emerging trends and new developments in monoclonal antibodies: A scientometric analysis (1980-2016). Hum Vaccin Immunother 13: 1-10, 2017.

27. Marcu DR, Ionita-Radu F, Iorga LD, Manea M, Socea B, Scarneciu I, Isvoranu G, Costache R, Diaconu CC and Bratu OG: Vascular involvement in primary retroperitoneal tumors. Rev Chim 70: 445-448, 2019.

28. Marcu RD, Diaconu CC, Constantin T, Socea B, Ionita-Radu F, Mischianu DLD and Bratu OG: Minimally invasive biopsy in retroperitoneal tumors (Review). Exp Ther Med 18: 5016-5020, 2019.

29. Foster GR, Coppola C, Derbala M, Ferenci P, Orlandini A, Reddy KR, Tallarico L, Shiffman ML, Ahlers S, Bakalos G, et al; GUARD-C Study Group: Impact of safety-related dose reductions or discontinuations on sustained virologic response in $\mathrm{HCV}$-infected patients: Results from the GUARD-C cohort. PLoS One 11: e0151703, 2016.

30. Crisu GC, Ionita-Radu F, Costache RS, Balaban VD, Nuta P, Stoica V, Vutcan LO, Stefan I, Naftanaila FM and Jinga M: Efficacy and safety of ombitasvir/paritaprevir/ritonavir + dasabuvir and ribavirin in patients with compensated HCV cirrhosis. Rom J Mil Med 122: 22-26, 2019. 
31. Sirbu CA, Budisteanu M and Falup-Pecurariu C: Monoclonal antibodies - A revolutionary therapy in multiple sclerosis. Neurol Neurochir Pol 54: 21-27, 2020

32. Mantegazza R and Antozzi C: When myasthenia gravis is deemed refractory: Clinical signposts and treatment strategies. Ther Adv Neurol Disord 11: 1756285617749134, 2018.

33. Edvinsson L: CGRP antibodies as prophylaxis in migraine. Cell 175: 1719, 2018

34. Institute for Safe Medication Practices (ISMP): News Item ISMP reports on safety of new migraine preventives. Reactions Weekly 1768: 2, 2019.

35. American Headache Society: The American Headache Society position statement on integrating new migraine treatments into clinical practice. Headache 59: 1-18, 2019.
36. Carmine Belin A, Ran C and Edvinsson L: Calcitonin generelated peptide (CGRP) and cluster headache. Brain Sci 10: 30, 2020.

37. Kuroda $\mathrm{H}$ and Fujihara K: Current status and prospects of complement-targeting therapy for neuromyelitis optica. Brain Nerve 71: 573-580, 2019 (In Japanese)

38. Oyama M, Okada K, Masuda M, Shimizu Y, Yokoyama K, Uzawa A, Kawaguchi N, Ikeguchi R, Hoshino Y, Hatano T, et al: Suitable indications of eculizumab for patients with refractory generalized myasthenia gravis. Ther Adv Neurol Disord 13: $1756286420904207,2020$. 